\title{
Viability of ceramic residues in lime-based mortars
}

\author{
Matias G. ${ }^{1}$, Faria P. ${ }^{2}$, Torres I. ${ }^{3}$ \\ 1. ITeCons - Instituto de Investigação e Desenvolvimento Tecnológico em Ciências da Construção. \\ ginamatias@itecons.uc.pt \\ 2. NOVA University of Lisboa, paulina.faria@fct.unl.pt \\ 3. Universidade de Coimbra.itorres@dec.uc.pt
}

\begin{abstract}
When we approach the subject of construction and rehabilitation of buildings we necessarily must think about external wall coatings as they are the elements more exposed to climate actions, mechanical and environmental conditions and, consequently, the first to be deteriorated and to need rehabilitation.

In what concerns the replacement of old plasters and renders, air lime mortars are normally the ones that are more compatible with the existing elements, but that have some limitations due to its slow setting time. As an alternative we may use natural hydraulic lime mortars.

We know that brick dust and grains have been widely used in mortars in the past, improving its characteristics, and that actually there are many kinds of ceramic residues that are byproducts of industry and are normally carried into landfills.

Within this context and associating the improvement of mortars characteristics to the necessity of sustainable construction practices, some mortars, formulated based on air lime or natural hydraulic lime, with the addition of ceramic residues, have been recently studied.

The aim of this paper is to present the experimental work that has been developed concerning the behaviour of two types of these lime mortars with ceramic residues. Characteristics, particularly in terms of flexural and compressive resistances, capillary water absorption and water vapour permeability will be discussed.

Comparison will be made between the characteristics of the mortars made with the two limes, and of mortars made with those limes with partial substitutions of siliceous sand by different types of ceramic residues. It will be possible to draw same conclusions about the interest and viability of recycling the ceramic residues as aggregates, its contribution as pozzolan and filler, and also if natural hydraulic limebased mortars can be a good alternative to air lime-based mortar for ancient masonry.
\end{abstract}

Keywords: air lime mortars, natural hydraulic lime mortars, ceramic residues.

\section{Introduction}

First signs of lime mortars with ceramics incorporation appear in 3000 A.C. buildings, during Babylonian Empire (Moropoulou 2005). However, it is during Roman Empire ( ${ }^{\text {nd }}$ cent. BC) that brick shards introduction in mortars arises and the technique would ultimately be spread through all South Europe, North Africa and Asia. Catone and Vitruvius were, on that period, the main authors to characterize and register this type of solution (Baronio 2006). They were applied with some different designations: "cocciopesto", "opus testaceum", "surkhi”, "homra", "horasan”, among others (Böke 2006, Bakolas 1998, Moropoulou 2005, O’Farrell 2006). Brick shards were introduced in mortars as dust, to act as pozzolans or filler, or in bigger granular sizes as a partial replacer of aggregates. Each fraction's introduction depended, essentially, on the type of mortar and its function - in plasters, smaller particles were used while in masonry mortars, for example, granular particles could be used (Moropoulou 2005). It is possible to find, in Portugal, some signs of these types of mortars, in archaeological sites where Roman Empire ruins are found, such as Troia and Conimbriga. 
From the functionality point of view, and considering some characterization works that have been already performed, air lime mortars and hydraulic lime mortars incorporating these materials have revealed improved behaviour, when compared with simple lime mortars. The seeming hydraulic behaviour of lime mortars with calcinated clays it is due to pozzolanic reactions developed, conditioned by aspects such as smaller particles' specific surface and the amounts of silica and alumina in amorphous state. When combined with calcium hydroxide contained in lime, silica and alumina from ceramic products generate silicates and aluminates which provide hydraulic properties to mortars. According to major authors, the amount of silica and alumina is one of the most essential conditions to reactivity. However, these materials should appear in amorphous state, which is mainly conditioned by clays calcination temperatures (Böke 2006). It is believed that, for most of the argillaceous raw materials, ideal calcination temperatures goes around $800{ }^{\circ} \mathrm{C}$ to $1000{ }^{\circ} \mathrm{C}$, depending on the author (Charola 2005, Böke 2006, Toledo Filho 2007, Pereira-de-Oliveira 2012). On the other hand, when used in a granular way, residues could develop cohesion mechanisms with the binder, whose behaviour is still not well known (Böke 2006).

As a substitute of commonly used aggregates in mortars or as dust, the use of ceramics waste presents several advantages, from the economic, ecologic and energetic point of view. As dust, when pozzolanic reactions occur, this product might contribute to conventional binders' consume reduction. In this way, it is possible to reduce energetic consumptions due to raw materials' calcination at high temperatures and also to reduce $\mathrm{CO}_{2}$ emissions (Toledo Filho 2007).

As an aggregate partial replacer, ceramic residues can contribute to the reduction of use of natural resources and prevent the dangerous environmental impacts caused by natural minerals' extraction. Generally, this proposal of industrial ceramic waste recovery will allow an actual solution for wastes that in most of the cases are disposed into landfills.

In this study, some air and hydraulic lime mortars were prepared, with residues from ceramic industries of central region of Portugal. These residues were mainly obtained from brick, tile and decorative pot production. After milling, the residues, that according to producers were calcinated at temperatures between $900{ }^{\circ} \mathrm{C}$ and $1000{ }^{\circ} \mathrm{C}$, were introduced into lime mortars as a replacer of the common aggregate with different proportions. This analysis allowed the understanding of the influence of each kind of residue in mechanical and physical behaviour of the mortars. It is presented a brief characterization of fresh state mortars. Mechanical strength, water vapour permeability and water absorption due to capillary action were also determined at distinct ages (28, 60 and 120 days).

With this work it is intended to extend the knowledge of viable solutions for old buildings recovery mortars, as well as to create guidelines that will allow the generation of real and applicable products. This type of mortars could produce solutions to problems such as incompatibility between available recent products and old supports or existing mortars, not forgetting the environmental, economic and energetic causes, the engines for sustainability.

\section{Experimental procedure}

\subsection{Materials characterization}

Mortar were made using hydrated powder air lime and natural hydraulic lime as binders, a river sand and ceramic residues.

Air lime, designated as CL 90 according to EN 459-1:2010 standard, was produced by Lusical (designed as $\mathrm{H} 100$ ). Its $\mathrm{Ca}(\mathrm{OH})_{2}$ mininum content is $93 \%$. Natural hydraulic lime was provided by Secil Martingança and it is classified according to EN 459-1:2010 as NHL3.5. This product has a declared $\mathrm{Ca}(\mathrm{OH})_{2}$ content between $15 \%$ and $65 \%$ and less than $2 \%$ sulphates.

Ceramic residues collected from brick, tile and decorative pot industries were crushed, with a laboratory Retsch jaw crusher, with a $10 \mathrm{~mm}$ cribble. The material was characterized in what concerns to particle size distribution. Particle size distribution of the ceramic residues and of the siliceous sand used as mortar constituents, determined according to EN 933-1:1997, is presented in Figure 1. Loose bulk density was also determined to allow weight proportions' evaluation. The value obtained for the limes, the sand and for each residue's, determined according to EN 1097-3:1998, is presented in Table 1. 
Table 1: Loose bulk density, $\rho_{\mathrm{b}}$, of the materials

\begin{tabular}{ccccccc}
\hline Material & Brick $(\mathrm{B})$ & Tile $(\mathrm{T})$ & Pot $(\mathrm{P})$ & River Sand & CL & NHL3.5 \\
$\rho_{\beta}\left(\mathrm{Mg} / \mathrm{m}^{3}\right)$ & 1.10 & 1.17 & 0.99 & 1.54 & 0.36 & 0.81 \\
\hline
\end{tabular}

From the analysis of Figure 1it can be noticed that residues particle size distribution after crushing is quite similar to the one of river sand. They are distinguished essentially from the percentage of particles smaller than $0,063 \mathrm{~mm}$ that, in residues' cases, represent $10 \%$ of the sample. Smaller particles from river sand are practically residual.

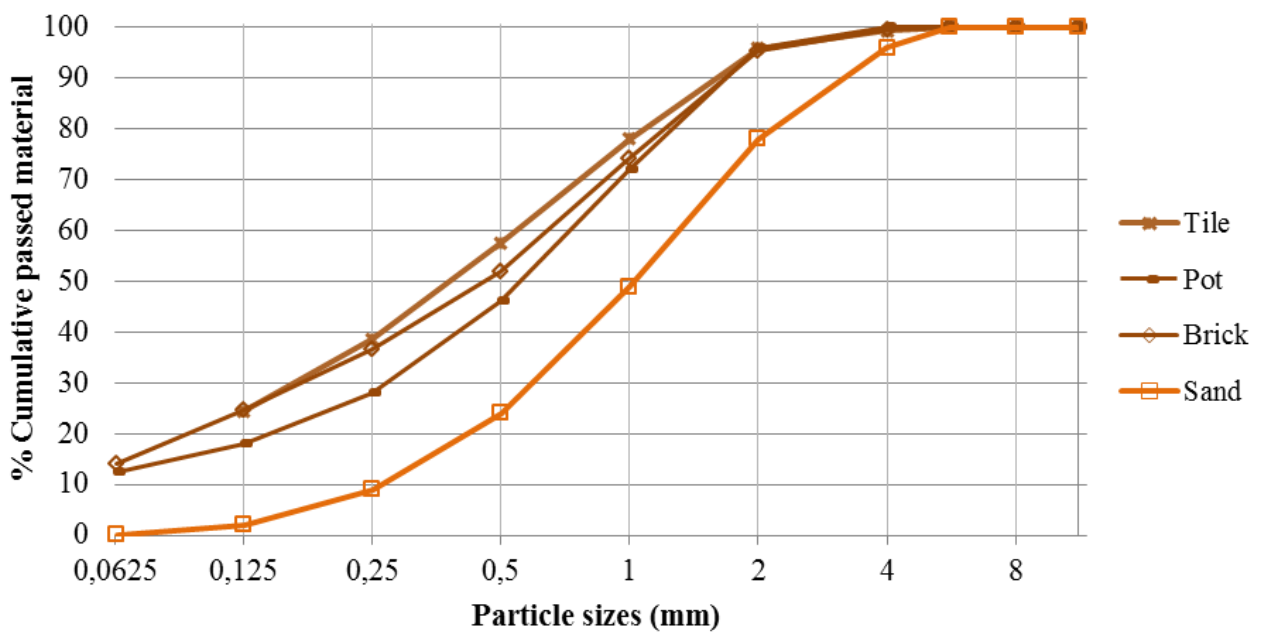

Figure 1: Ceramic residues and sand's particle size distribution

In terms of loose bulk density of the dry materials, all residues presented quite similar values, lower than river sand and close to hydraulic lime value. Air lime bulk density has the lowest value obtained.

\subsection{Mixtures characterization}

Several mortars' compositions were prepared with the materials described above. Main volumetric proportion was 1:3 (binder:agregate) and for each type of residue, 20\% and 40\% of the natural sand was replaced. Mortars with $20 \%$ of sand's substitution were designated with an L (Low) and mortars with 40 $\%$ of sands substitution were designated with an $\mathrm{H}$ (High). Mortars with brick residues were attributed B suffix, mortars with tile sharks, T, and mortars with decorative pot were attributed a P. Natural hydraulic lime mortars were designated with an NH prefix. Besides indicated mixtures, reference mortars without residues were also prepared and they were referenced with an $\mathrm{R}$. These mortars allowed the evaluation of each residue influence, as well as the influence of the substitution percentages.

All mixtures were prepared with water amounts that allowed a consistency in fresh conditions of [135:165] $\mathrm{mm}$, range that allow this type of lime-based mortars workability. This parameter was determined according to EN 1015-3:1999 standard (flow table method). Water/binder proportions were also determined and results are presented in Table 2 . Table 3 indicates volumetric and weight proportions applied.

Table 2: Water/binder ratio (w/b) and flow value (fv)

\begin{tabular}{ccccccccccccccc}
\hline Mortar & R & LB & HB & LT & HT & LP & HP & \multicolumn{1}{c}{ NHR NHLB NHHB NHLT NHHT NHLP NHHP } \\
\hline $\begin{array}{c}\mathrm{w} / \mathrm{b} \\
(\mathrm{m} / \mathrm{m})\end{array}$ & 2.85 & 2.21 & 2.56 & 2.62 & 2.35 & 2.35 & 2.63 & 0.91 & 1.02 & 1.06 & 0.99 & 1.08 & 0.98 & 1.07 \\
\hline $\mathrm{fv}(\mathrm{mm})$ & 147.6 & 150.8 & 152.9 & 151.3 & 153.2 & 151.4 & 151.0 & 151.8 & 143.1 & 141.8 & 164.6 & 162.3 & 154.8 & 148.9 \\
\hline
\end{tabular}


From fresh mortars, based on EN 1015-11:1999/A1:2006, cylindrical specimens for water vapour determination and prismatic specimens for mechanical strengths and water absorption were prepared. Specimens were kept in the first 5 days at $20{ }^{\circ} \mathrm{C}$ and $95 \%$ relative humidity (HR). They remained for 2 more days in $20{ }^{\circ} \mathrm{C}$ and $65 \% \mathrm{HR}$ and were demoulded. They remained in these conditions until the age of test. The incorporation of ceramic residues also acted as a pigment and the mortars became slightly coloured.

Table 3: Volumetric and weight proportions

\begin{tabular}{ccccccccc}
\hline \multirow{2}{*}{ Mortar } & CL & NHL3.5 & \multicolumn{3}{c}{ Residues } & Sand & $\begin{array}{c}\text { Volumetric } \\
\text { proportions }\end{array}$ & $\begin{array}{c}\text { Weight } \\
\text { proportions }\end{array}$ \\
\hline R & 1 & - & - & - & - & 3 & $1: 3$ & $1: 12,2$ \\
LB & 1 & - & 0,6 & - & - & 2,4 & $1: 0,6: 2,4$ & $1: 1,8: 10,2$ \\
HB & 1 & - & 1,2 & - & - & 1,8 & $1: 1,2: 1,8$ & $1: 3,6: 7,7$ \\
LT & 1 & - & - & 0,6 & - & 2,4 & $1: 0,6: 2,4$ & $1: 1,9: 10,2$ \\
HT & 1 & - & - & 1,2 & - & 1,8 & $1: 1,2: 1,8$ & $1: 3,9: 7,7$ \\
LP & 1 & - & - & - & 0,6 & 2,4 & $1: 0,6: 2,4$ & $1: 1,9: 10,2$ \\
HP & 1 & - & - & - & 1,2 & 1,8 & $1: 1,2: 1,8$ & $1: 3,9: 7,7$ \\
NHR & - & 1 & - & - & - & 3 & $1: 3$ & $1: 5,7$ \\
NHLB & - & 1 & 0,6 & - & - & 2,4 & $1: 0,6: 2,4$ & $1: 0,8: 4,5$ \\
NHHB & - & 1 & 1,2 & - & - & 1,8 & $1: 1,2: 1,8$ & $1: 1,6: 3,4$ \\
NHLT & - & 1 & - & 0,6 & - & 2,4 & $1: 0,6: 2,4$ & $1: 0,9: 4,5$ \\
NHHT & - & 1 & - & 1,2 & - & 1,8 & $1: 1,2: 1,8$ & $1: 1,7: 3,4$ \\
NHLP & - & 1 & - & - & 0,6 & 2,4 & $1: 0,6: 2,4$ & $1: 0,7: 4,5$ \\
NHHP & - & 1 & - & - & 1,2 & 1,8 & $1: 1,2: 1,8$ & $1: 1,5: 3,4$ \\
\hline
\end{tabular}

\subsection{Strength resistances}

Flexural and compressive strength resistances were determined, for each specimen, according to EN 1015-11:1999/A1:2006 standard specifications. For this purpose, three prismatic specimens were moulded, for each sample and curing period, with $40 \mathrm{~mm}$ x $40 \mathrm{~mm}$ x $160 \mathrm{~mm}$ dimensions. Specimens were kept in standard conditions until 28, 60 and 120 days. Compressive strength resistance was determined with one of the halves resultant from flexural strength resistance tests. Flexural strength results are indicated in Figure 2, and compressive strength results are presented in Figure 3.

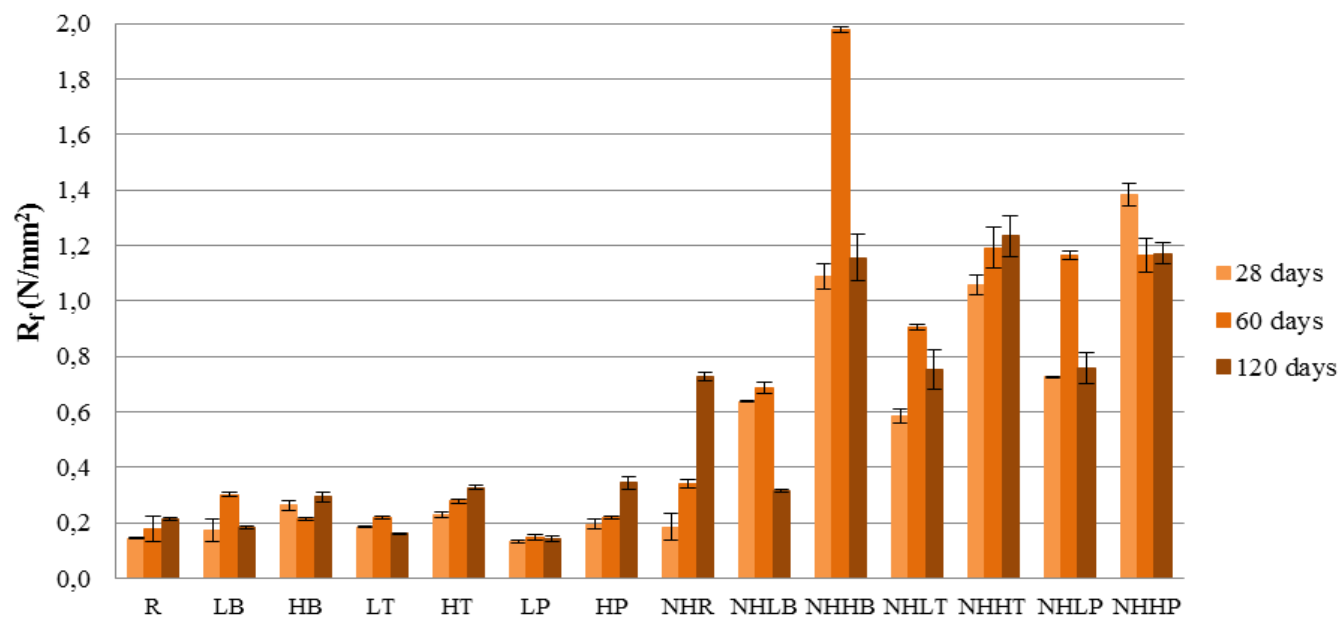

Figure 2: Flexural strength at 28, 60 and 120 days of curing 
It was observed that neither air lime mortars' flexural or compressive strength resistance presented a significant increase through time, except for mortars with high percentages of tile and pot residues. All mortars with high percentage of residues revealed clearly higher strength resistances. In all cases, mortars presented higher strength resistance values than both reference mortars, R and HR and in some cases resistances at 60 days curing were superior to ones obtained at 120 days.

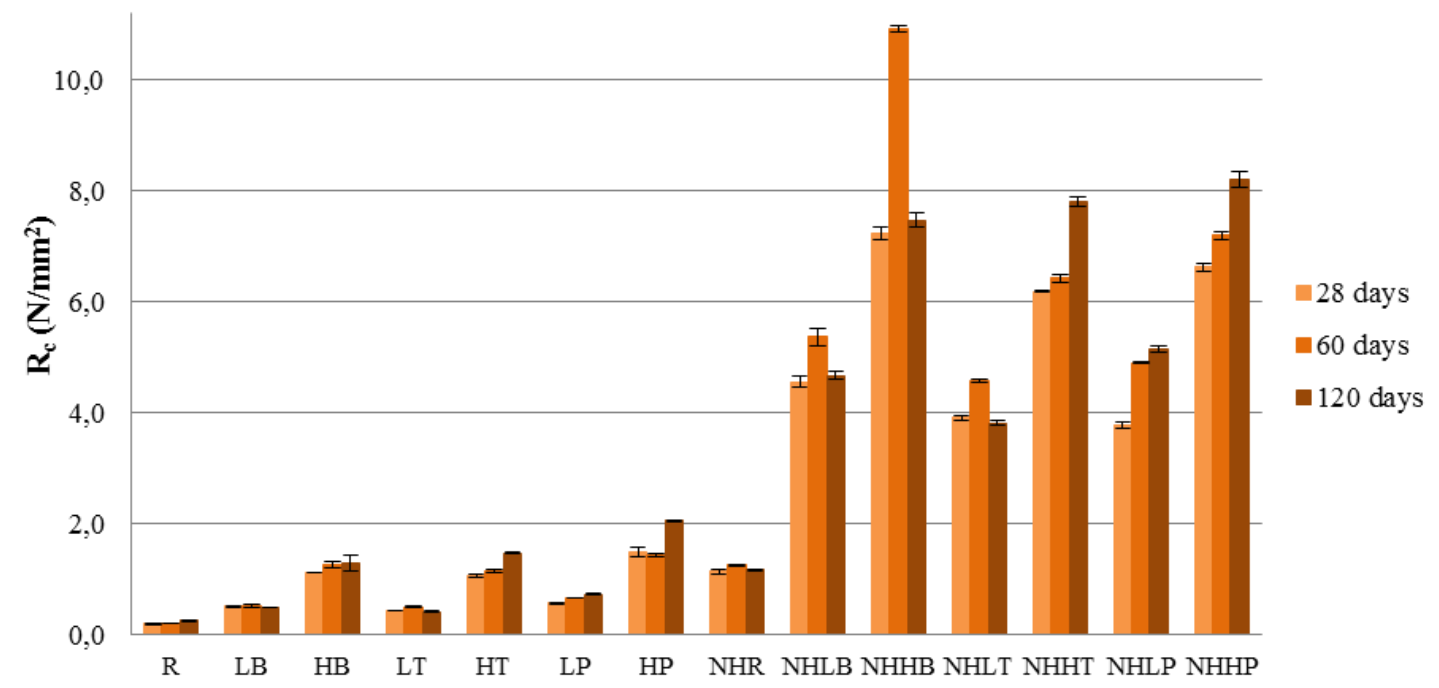

Figure 3: Compressive strength resistances at 28, 60 and 120 days of curing

\subsection{Water absorption due to capillary action}

Water absorption due to capillary action was determined at 28, 60 and 120 days, according to EN 15801:2009 standard recommendations, more appropriate to slow curing mortars as air lime ones. One of the two resultant halves from flexural resistant specimens was used and weightings were carried out at 5 , $10,15,30,60,90,120,180$ minutes and each 24 hours after first contact of the specimens with the water slide, until constant mass was reached. Water absorption coefficient, graphically determined, is represented in Figure 4. Figure 5 shows, as an example, $1^{\text {st }}$ hour's absorption curve, at 28 days of curing.

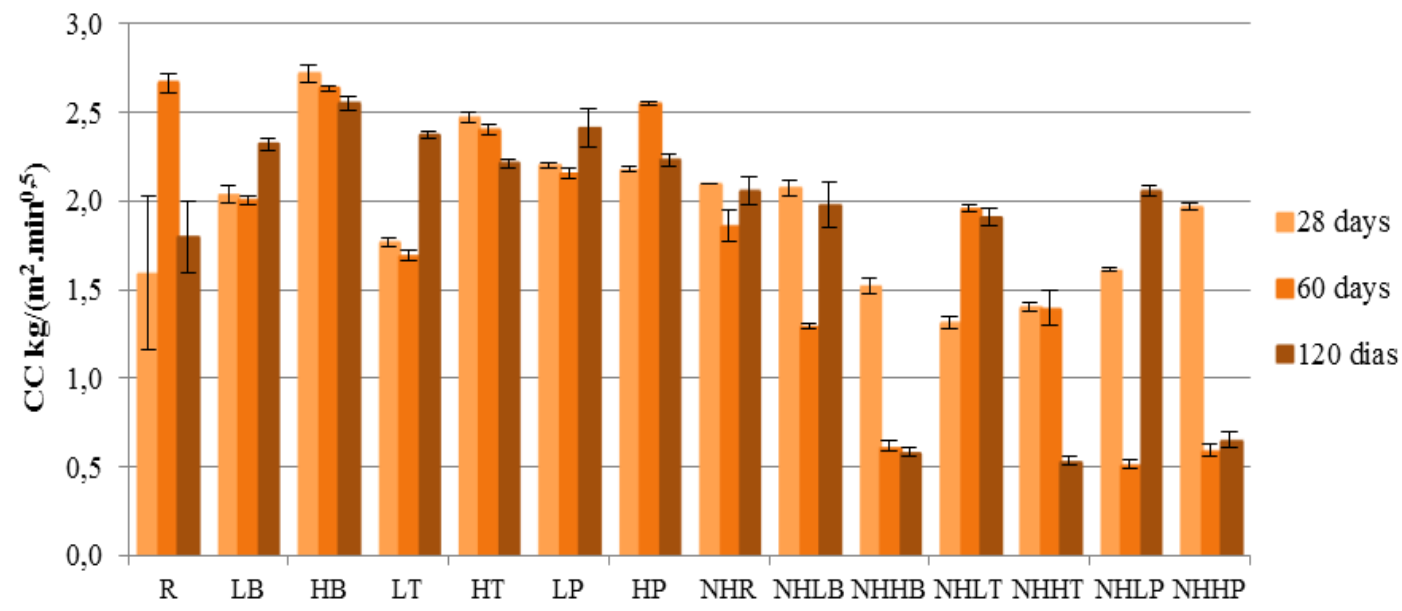

Figure 4: Capillary coefficient at 28, 60 and 120 days

Generally air lime mortars obtained higher capillary coefficient values. However, these ones also generated more uniform values in what concerns to residue type and curing period. Hydraulic lime mortars' capillary coefficients resulted in discrepant results that did not allow any evident conclusions. 
Nonetheless, at 120 days curing, hydraulic lime mortars with high residues' percentage obtained the lower water absorptions by capillary. Air lime mortars, at this period, resulted in higher water absorptions.

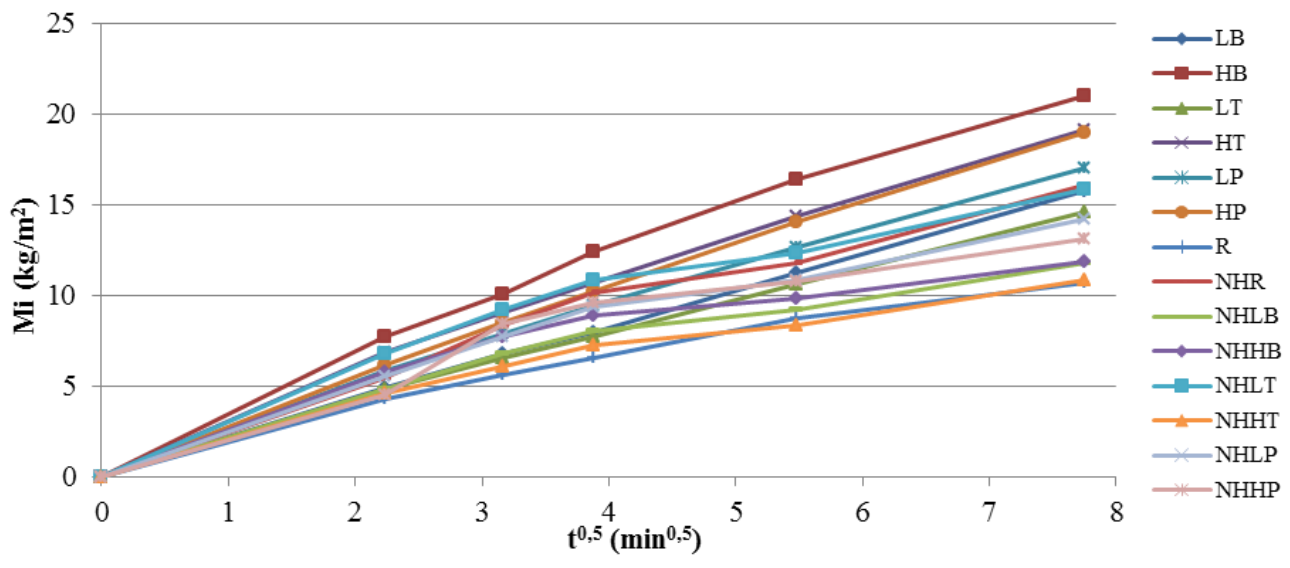

Figure 5: Water absorption due to capillary action, 28 days curing $\left(1^{\text {st }}\right.$ hour $)$

In what concerns to water absorption during the $1^{\text {st }}$ hour of test, represented in Figure 5, high residue percentage air lime mortars shown higher water absorption velocities (with higher water absorption's curve bent) and air lime mortars with tile residues presented lower water absorption velocities. In general, hydraulic lime mortars revealed slower water absorptions.

\subsection{Water vapour permeability}

Three circular specimens were prepared for each mortar, with an approximated diameter of $100 \mathrm{~mm}$ and thickness of $17 \mathrm{~mm}$. Following the procedure indicated by ISO 12572:2001 standard, wet cup method was selected. Tests were performed at 28, 60 and 120 days. Figure 6 shows the obtained results for water vapour permeability at indicated ages, as well as standard deviation associated to each result. Figure 7 presents the water vapour diffusion-equivalent air layer thickness values, $S_{d}$, which allows thickness evaluation of an equivalent air layer in terms of water vapour resistance.

In what concerns the type of binder, evident water vapour permeability differences were observed. Water vapour permeability values obtained for air lime mortars with residues are always higher than those with NHL3.5 and residues. The mortars with NHL3.5 and brick residues present the lowest water vapour permeability. The addition of ceramic residues decreases the permeability almost for all mortars but is more pronounced for mortars with brick residue and for higher percentage of substitution. .

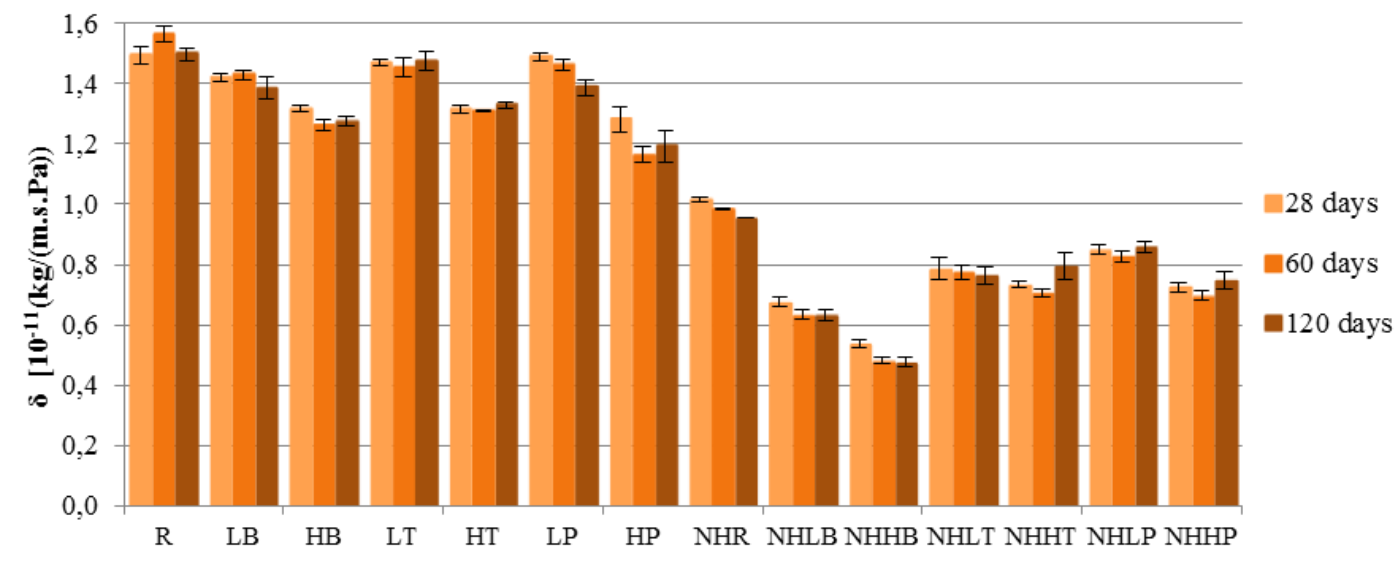

Figure 6: Water vapour permeability 
In what concerns to water vapour diffusion-equivalent air layer thickness, all air lime mortars obtained quite uniform values, significantly lower than ones obtained from hydraulic lime mortars. In the case of the last ones it was possible to observe evident differences related to substitution's percentage: low residues' percentage mortars presented lower water vapour diffusion-equivalent air layer thickness values, as expected considering water vapour permeability results. Highest water vapour resistance mortar was the one with hydraulic lime and high brick residue's percentage. Also, in both water vapour permeability and air layer thickness, significant standard deviations were not detected.

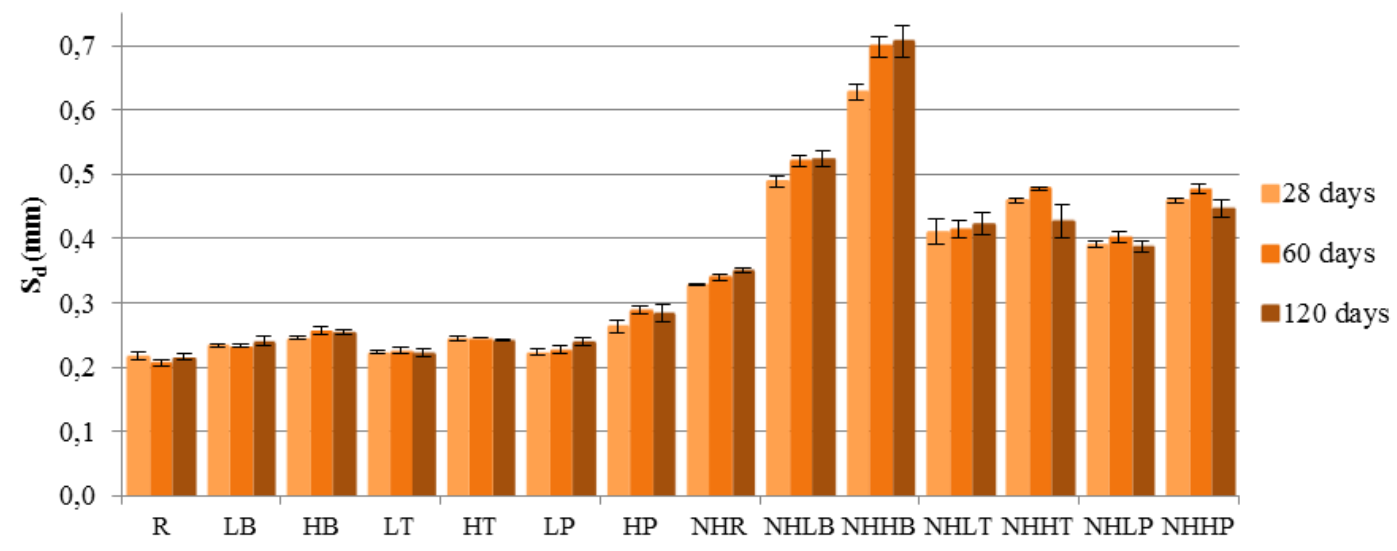

Figure 7: Water vapour diffusion-equivalent air layer thickness

\section{Discussion}

Regarding to mechanical behaviour, strength resistances of air lime mortars with high percentage of residues from tile and pot residues might be related to some kind of pozzolanic reactivity. The fact that all mortars with residue presented higher resistance values than the correspondent reference ones may also be an indicator of this type of reaction. These results may also be related with the substitution of common rounded aggregates by irregular and angular surface residues that could contribute to materials cohesion. It was not found any reason for the fact that some mortars obtained higher values at 60 days than at 120 days curing. This situation should be explored in following studies to see if there are instable products that may be formed at around two months of age and then are transformed in others. The fact that mortars do not reach the standardized strength must be due to the use of different aggregates, water/binder ratio and mixture procedures.

In terms of water absorption due to capillary action at $1^{\text {st }}$ test hour, hydraulic lime mortars presented more satisfying values, for their slower water absorption. Generally, this parameter is directly related to water vapour permeability: higher water vapour permeability mortars resulted in higher water absorption due to capillary action. Thereby it is possible to relate water absorption with mortars' porous structure, as this occurs essentially due to smaller pores.

In what concerns to water vapour permeability, all mortars with high percentage of residue revealed lower permeability values when compared to correspondent low residue percentage mortars. This event might be related to higher amounts of residues' small particles, which leads to closer porous structures. The absence of significant differences through time might be an indication of the unchanged porous structures due to carbonation and hydration process.

When requirements for old buildings substitution mortars, applied as renders, plasters or repointing (Veiga 2010) are analysed, water vapour diffusion-equivalent air layer thickness should present values inferior to $0.1 \mathrm{~mm}$. In this study, none of the mortars fulfils this requirement. However, air lime mortars obtained close values, whereby they might be considered adequate for the effect that is purposed. In what concerns to capillary coefficient, it is defined an interval from $1.0 \mathrm{~kg} /\left(\mathrm{m}^{2} / \mathrm{min}^{1 / 2}\right)$ to $1.5 \mathrm{~kg} /\left(\mathrm{m}^{2} / \mathrm{min}^{1 / 2}\right)$. Most hydraulic lime studied mortars, in different curing periods, presented quite close values and air lime mortars present slightly higher values. Mortars which revealed better capillary behaviour were the ones with tile residues. Veiga (2010) also defines adequate strength resistance values: flexural strength resistance should be between $0.2 \mathrm{~N} / \mathrm{mm}^{2}$ and $0.8 \mathrm{~N} / \mathrm{mm}^{2}$. Air lime mortars obtained values quite close 
from the minimum value defined and low residue substitution hydraulic lime mortars presented higher values but very close to maximum flexural strength resistance defined. In this way, these two groups seemed to be the ones with better flexural strength behaviour. In what concerns to compressive strength resistance, ideal values might be between $0.4 \mathrm{~N} / \mathrm{mm}^{2}$ and $3 \mathrm{~N} / \mathrm{mm}^{2}$. Air lime mortars with high residue substitution fulfil this requirement. Natural hydraulic lime mortars with low residue substitution are quite close the maximum limit defined. It should be taken into account that test methodologies might have some differences and, as so, direct results comparison must be careful.

\section{Conclusions}

In mechanical behaviour terms, air lime mortars with high residue substitution and natural hydraulic lime mortars with low residue substitution have shown a better performance. Through the analysis carried out, it may be said that there is clear evidence of the existence of some pozzolanic reactivity.

In what concerns to physical behaviour, it was observed that water vapour permeability and water absorption due to capillary action are closely related to porous structure and small pores amount and it was concluded that residues' material properties might have an insignificant influence in water absorption properties. Generally, obtained results were quite satisfying when compared to reference documents consulted.

Globally, it is considered that studied mortars have a quite satisfying behaviour and the residues inclusion may improve the characteristics of common lime mortars. Some natural hydraulic lime mortars with residues may present too high resistance for some old buildings; however formulations of mortars with lower binder proportions may be tested and its characteristics might be adjusted to the characteristics of the existent buildings.

The fact of having mortars that can even improve its behaviour when formulated with ceramic residues that are generally land filled encourage the continuity of this study.

\section{Aknowledgments}

The authors would like to thank the FCT-Fundação para a Ciência e Tecnologia for its support through the project EXPL/ECM-COM/0928/2012-Incorporation of ceramic residues in repair mortars.

\section{References}

Baronio G., Binda L., Lombardini N. (2006) The role of brick pebbles and dust in conglomerates based on hydrated lime and crushed bricks, Constr Build Mater, 11, 33-40.

Böke, H.; Akkurt, S.; İpekoğlu, B.; Uğurluet, E. (2006) Characteristics of brick used as aggregate in historic brick-lime mortars and plasters, Cem Concr Res, 36, 1115-1122.

Bakolas, A.; Biscontin, G.; Moropoulou, A.; Zendri, E. (1998) Characterization of structural byzantine mortars by thermogravimetric analysis, Thermochimica Acta, 321, 151-160.

Charola E.; Faria-Rodrigues, P.; McGhie, A.; Henriques, F. (2005) Pozzolanic components in lime mortars: correlating behaviour, composition and microstructure. Restoration of Buildings and Monuments, 11 (2),111-118.

Moropoulou, A.; Bakolas, A.; Anagnostopoulouet, S. (2005) Composite materials in ancient structures, Cement \& Concrete Composites, 27, 295-300.

O'Farrell, M.; Sabir B., B.; Wild, S. (2006) Strength and chemical resistance of mortars containing brick manufacturing clays subjected to different treatments, Cement \& Concrete Composites, 28, 790-799.

Pereira-de-Oliveira, L.A.; Castro-Gomes, João P.; Santos, Pedro M.S. (2012) The potential pozzolanic activity of glass and red-clay ceramic waste as cement mortars components, Constr Build Mater, 31, 197-203.

Toledo Filho, R.D.; Gonçalves, J.P.; Americano, B.B.; Fairbairn, E.M.R. (2007) Potential for use of crushed waste calcined-clay brick as a supplementary cementitious material in Brazil, Cem Concr Res, 37, 1357-1365.

Veiga, M., Fragata, A., Velosa, A., Magalhães, A. e Margalha, G. (2010) Lime-based mortars: viability for use as substitution renders in historical buildings, International Journal of Architectural Heritage, $4,177-195$. 